Journal of Engineering and Applied Sciences 14 (Special Issue 7): 10043-10051, 2019

ISSN: 1816-949X

(C) Medwell Journals, 2019

\title{
Synthesis and Characterization of Some Novel Monomers and Copolyesters Containing Bispyrazole or Bisdihydroisoxazole with Studying the Effect of $\mathrm{TiO}_{2}$ Nanoparticles on their Electrical Conductivity
}

\author{
${ }^{1}$ Mohammed Abbas Fadhil Al-Samarrai, ${ }^{1}$ Luay Alidhahi and \\ ${ }^{2}$ Osamah Mohammed Mahdi Alnaisani \\ ${ }^{1}$ Department of Applied Chemistry, College of Applied Sciences, University of Samarra, \\ Samarra, Iraq \\ ${ }^{2}$ Ministry of Education, Department of Samarra Education, Governorate Salah Adin, \\ Salah Adin, Iraq
}

\begin{abstract}
$\overline{\text { Abstract: In this study, attempting to obtain new electrically-conducting polymers, six conjugated copolyesters }}$ have been synthesized. First, bispyrazole and bisdihydroisoxazole heterocyclics monomers were obtained from close-closing of bischalcone derivatives by hydrazine and hydroxylammonium chloride, respectively. The Bispyrazole Heterocyclic monomer (BHZH) was used in the preparation of PHZT, PHZP, PHZO and dihydroisoxazole heterocyclic monomer (BHAH) was used in the preparation of PHAT, PHAP, PHAO. The structure of the monomers and the repeating units present in the copolyesters chain was confirmed by FT-IR, 1H-NMR spectroscopic techniques, Differential Scanning Calorimetry (DSC), X-Ray Diffraction (XRD) also the thermal properties of these copolyesters were evaluated by Thermo Gravimetric Analysis (TGA), the electrical conductivity results indicated the prepared copolyesters lie semiconductors region, in addition. The effect of increasing the $\mathrm{TiO}_{2}$ nanoparticles concentration as a filler and the frequency on the electrical conductivity of the prepared copolyesterwas analyzed, the results showed the increase of electrical conductivity with increasing concentration of $\mathrm{TiO}_{2}$ nanoparticles and the frequency.
\end{abstract}

$\underline{\text { Key words: } \text { Bispyrazole, bisdihydroisoxazole, copolyesters, } \mathrm{TiO}_{2} \text { nanoparticles, electrical conductivity, XRD }}$

\section{INTRODUCTION}

Conducting polymers (Cps) have attracted significant attention due to their use in commercial applications such as electronic elements (Lu et al., 2011), rechargeable batteries (Wang, 2015; Kenin et al., 2018), optical switching elements (Davidenko and Kokozay, 2017), sensors (Dodabalapur, 2006; Kumar et al., 2015), electrostatic charge dissipation, electromagnetic interference EMI shielding (Sudirman et al., 2012; Chandrasekhar and Naishadham, 1999), excellent NLO properties (Pietrangelo et al., 2008), molecular devices and membranes which originates from their high electrical conductivity (Hackett et al., 2017; Bryan et al., 2016). Cps are an superb choice because of their long p-conjugation length with their good electrical conductivity $\left(10^{-3}-10^{-5}\right) \mathrm{s} / \mathrm{cm}$ (Phang et al., 2008) and it have surprising properties of having high electrical conductivity and can display a range of properties from semiconducting to close metallic behavior or it can have a greater range of electrical conductivity than inorganic semiconductors (Dubey and Leclerc, 2011; Kose and Ramteke, 2012).
Most electrically-conducting polymers are containing conjugated backbone, i.e., alternating double and single bounds (Mahmood, 2017) which is accepted to be not only a basic condition for electrical conductivityas well as it is also a major cause of the characteristic ability and good mechanical properties of these polymers (Khattab, 2008). The synthesis of electrically conductivities polymers with conjugated $-\mathrm{C}=\mathrm{C}$ - bonds requires the controlled coupling of a large number of monomers (Khattab, 2007). So, through simple modifications of their molecular structure, their physical and chemical properties can be adjusted in a fairly large range such as definite structures were incorporated in the backbone of the for studying the effect of molecular structure on the electronic, physical and electrical properties of the polymers (Khattab, 2008) also polymer adjustments give methods for studying the effects of chain flexibility (Amborski, 1962), symmetry and molecular hardness on conductivity and knowledge of the structural reliance of conductivity with the mechanism of conduction in polymers will allow the synthesis and manufacture of conductive polymers films (Imam, 2013; 
Vilcakova et al., 2002), the attention in conjugated polymers has increased because these polymers combine some properties of both metals and polymers (Caseri, 2000).

Nanocomposites are a modern category of materials that havehigh physical, thermal and mechanical properties compared withtraditional composites (micro composites) (Balazs et al., 2006; Hamming et al., 2009) and polymers nanocomposite is a polymer that has been reinforced with a little quantity ( $<5 \%$ wt.) of nanosized particles (Levitsky et al., 2009), the heterogeneous-conducting polymer nanocomposites principally for organic-inorganic nanocomposite have an interest of scientists in the last decade (Su and Kuramoto, 2000) owing to their enhanced properties arising from the reinforcement of nanofiller, so, nanoscale reinforcement materials using to improve the electrical and optical properties of the polymers (Bora et al., 2013; Potts et al., 2011) such as thin films of nanocrystalline $\mathrm{TiO}_{2}$ have significant applications in the field of optoelectronic materials (Potts et al., 2011) also considered photocatalytic material (Fleming et al., 2005; Arango et al., 1999) can be used to form thin films in dye-sensitized solar cells and anti-reflection coatings (Okada et al., 2006). Although, there are many reports on the heterogeneous-conducting polymer nanocomposites but one special interest is the incorporation of inorganic nanoclusters with conducting polymers because the resulting nanocomposites may possess unique electrical and optical properties ( $\mathrm{Su}$ and Kuramoto, 2000; Yavuz and Gok, 2007). However, there are no reports on study of the synthesis and characterization of copolyesters containing bispyrazolines and bisdihydroisoxazole moiety as a different heterocyclic ring which aromatic heterocyclic has less than aromatic nature such as a furan, pyrrole and thiophene. So, this study deals with the synthesis of copolyesters by the poly condensation of (BHAH or $\mathrm{BHZH})$ and diacidchlorides and also studyingthe effect of $\mathrm{TiO}_{2}$ nanoparticle on their electrical conductivity.

\section{MATERIALS AND METHODS}

Experimental: Terephthalaldehyde, oxalyl chloride (Sigma Aldrich), terephthalic acid, phthalic acid, acetone, 4-hydroxyacetophenone (Spectrochem Puriss grade), hydroxylamine hydrochloride, 4-hydroxybenzaldehyde (LobaChemie AR), hydrazine hydrate (80\%) (Merck), $\mathrm{TiO}_{2}$ nanoparticles were purchased from (Sigma Aldrich). Thionyl chloride sulphuric acid and sodium hydroxide (Rankem) were used as received. All other materials were used after purification.

Synthesis of Bischalconediol (BH): (1, 4-phenylene) bis (1-(4-hydroxyphenyl) prop-2-en-1-one): method preparing bis-chalcone compounds are same stated in the study (Podkoscielny and Kultys, 1976) syntheses 1-4 should do described in the study two similar molar quantity of 4-hydroxyacetophenone (2.76 g, $0.02 \mathrm{~mol}$ ) was added into conical flask $100 \mathrm{~mL}$ and was dissolved in $25 \mathrm{~mL}$ of ethanol absolute. The $20 \%$ aqueous $\mathrm{NaOH}$ solution ( $2 \mathrm{~g}$, $0.02 \mathrm{~mol}$ ) was poured gently into the conical flask containing 4-hydroxyacetophenone and the mixture was stirred for about $10 \mathrm{~min}$. Terephthaldehyde (1.34 g, 0.01 mol) was added into conical flask. The mix was mixed vigorously at $0-4^{\circ} \mathrm{C}$ for $4 \mathrm{~h}$ and kept in the refrigerator for $24 \mathrm{~h}$, 3M glacial acetic acid was added until the solution was neutralized (Konagaya and Tokai, 2000) as yellowish green powder; yield: $60 \%$. The obtained precipitate did filtrated off washed and dried and recrystallized of ethanol. The completion of this reaction was monitored by TLC (methanol: Benzene) (1:4).

Monomer synthesis of (BHAH): 4, 4-(1, 4-phenylene bis (isoxazole-5, 3-diyl)) diphenol: according to general procedure, compound Bischalcone (BH) (1.85 g, $0.005 \mathrm{~mol}$ ) was dissolved in $25 \mathrm{~mL}$ of ethanol and sodium hydroxide solution $(0.5 \mathrm{~g} \mathrm{NaOH}$ in $10 \mathrm{~mL}$ of water) was poured gently into the conical flask containing bischalcone and was stirred for about $10 \mathrm{~min}$, hydroxylamine hydrochloride $(1.39 \mathrm{~g}, 0.02 \mathrm{~mol})$ was dissolved in $25 \mathrm{~mL}$ of ethanol and was added into conical flask containing bischalcone MA. The mixture was refluxed with stirring on a water bath at $70^{\circ} \mathrm{C}$ for $7 \mathrm{~h}$ then the mixture was cooled with stirring at room temperature overnight, the precipitate was concentrated under vacuum, poured into ice water and after that 3M $\mathrm{HCl}$ was added until the solution was neutralized as yellowish green powder; yield: 73\%. The obtained precipitate was filtered off washed and dried and recrystallized from ethanol. The completion of the reaction was monitored by TLC (methanol: Benzene) (1:4) (Majeed, 2013).

Synthesis of monomer (BHZH): 4, 4-(1, 4-phenylene bis (1H-pyrazole-5, 3-diyl)) diphenol: according to general procedure, compound a mixture of Bischalcone $(\mathrm{BH})$ (1.85 g, $0.005 \mathrm{~mol}$ ) and hydrazine hydrate (80\%) (1 g, $0.02 \mathrm{~mol})$ in ethanol $(30 \mathrm{~mL})$ was heated under reflux with stirring on a water bath at $70^{\circ} \mathrm{C}$ for $10 \mathrm{~h}$ then the mixture was cooled with stirring at room temperature overnight, the precipitate was concentrated under vacuum, poured into ice water and after that $3 \mathrm{M} \mathrm{HCl}$ was added until the solution was neutralized as yellowish green powder; yield: 60\%. The obtained precipitate was filtered off, washed, dried and recrystallized from ethanol. The completion of the reaction was monitored by TLC (methanol: Benzene) (1:4) (Majeed, 2013).

General preparation of phthaloyl chloride of terephthaloyl chloride oxalyl chloride (Podkoscielny and Kultys, 1976; Konagaya and Tokai, 2000): Phthaloyl chloride was prepared by refluxing phthalic acid with an excess amount of thionyl chloride in the presence of a slight amount of DMF as catalyst for $4 \mathrm{~h}$. 
The unreacted thionyl chloride was distilled off under vacuum. The obtained product was solidified on cooling in an ice bath.

General synthesis of polymer 1-6: The monomer BHZH or BHAH (0.003 mol) was dissolved in DCM 20 and $2 \mathrm{~mL}$ of pyridine used in a three-necked $125 \mathrm{~mL}$ round flask, solution of (terephthaloyl chloride, phthaloyl chloride or oxalyl chloride) $(0.003 \mathrm{~mol})$ in $5 \mathrm{ML}$ of DCM did moderately add inside $5 \mathrm{~min}$ through the funnel at $0-5^{\circ} \mathrm{C}$ temperature below strong stirring. The mix was stirred continuously at RT to $30 \mathrm{~min}$ in a nitrogen atmosphere. The reaction was stirred maintained overnight at RT and then acidified by 1:1 dilHCl. The precipitated polyester did washed by methanol, filtered and dried in a vacuum oven.

Characterization and analytical techniques: FTIR spectra: FTIR spectra of $\mathrm{M} 1(\mathrm{KBr}) \quad v\left(\mathrm{~cm}^{-1}\right)$ : 3448 $\mathrm{s}(\mathrm{C}-\mathrm{OH}) 1685 \mathrm{~s}(\delta \mathrm{C}=\mathrm{O}), 1596-1501 \mathrm{~s}(\mathrm{C}=\mathrm{CAr}), 1342$ m(C-O). ${ }^{1} \mathrm{H}-\mathrm{NMR}$ spectra (DMSO-d ${ }^{6}$ ) $\delta$ ppm: 6.65-6.94dd (4H, CH-Ar), $7.42-7.73(4 \mathrm{H}, \mathrm{CH}=\mathrm{CH}), 7.93-8.06 \mathrm{dd}$ (4H, CH-.Ar), 8.12 (4H, CH-Ar), 10.03 (2H-OH).
FTIR spectra of BHAH(KBr) v $\left(\mathrm{cm}^{-1}\right)$ : $3523 \mathrm{~s}(\mathrm{C}-\mathrm{OH}) 1658$ $\mathrm{s}(\delta \mathrm{C}=\mathrm{N}), 1587-1508 \mathrm{~s}\left(\mathrm{C}=\mathrm{C}_{\mathrm{Ar}}\right), 1359 \mathrm{~m}(\mathrm{C}-\mathrm{O}) .{ }^{1} \mathrm{H}-\mathrm{NMR}$ spectra (DMSO-d $\left.{ }^{6}\right) \delta$ ppm: $6.86(2 \mathrm{H}, \mathrm{CH}=\mathrm{C}), 7.21-7.33$ dd (4H, CH-Ar), 7.49-7.67dd (4H, CH-.Ar), 7.86-8.10 dd (4H, CH-Ar), 9.90 (2H-OH), 10.51(2H NH). FTIR spectra of BHZH $(\mathrm{KBr}) v\left(\mathrm{~cm}^{-1}\right)$ : $3226 \mathrm{~s}(\mathrm{C}-\mathrm{OH}) 1620 \mathrm{~s}(\delta \mathrm{C}=\mathrm{N})$, 1569-1508s $\left(\mathrm{C}=\mathrm{C}_{\mathrm{Ar}}\right), 1359 \mathrm{~m}(\mathrm{C}-\mathrm{O}) .{ }^{1} \mathrm{H}-\mathrm{NMR}$ spectra $\left(\mathrm{DMSO}^{6} \mathrm{~d}^{6}\right) \delta \mathrm{ppm}$ : $6.74(2 \mathrm{H}, \mathrm{CH}=\mathrm{C}), 7.15-7.33$ dd $(4 \mathrm{H}$, CH-Ar), 7.50-7.77 dd (4H, CH-.Ar), 7.88-7.96 dd (4H, $\mathrm{CH}-\mathrm{Ar}), 10.17$ 2H-OH. FTIR spectra of PHAT (KBr) $v\left(\mathrm{~cm}^{-1}\right): 3340 \mathrm{~m}(\mathrm{~N}-\mathrm{H}), 1733 \mathrm{~m}(\delta \mathrm{C}=\mathrm{O}$ ester $), 1683 \mathrm{~m}$ $(\mathrm{C}=\mathrm{N}), 1600-1506 \mathrm{~m}\left(\mathrm{C}=\mathrm{C}_{\mathrm{Ar}}\right), 1263 \mathrm{~m}(\mathrm{C}-\mathrm{O})$. FTIR spectra of PHAP $(\mathrm{KBr}) v\left(\mathrm{~cm}^{-1}\right): 1737 \mathrm{~m}(\delta \mathrm{C}=\mathrm{O}$ ester $)$, $1689 \mathrm{~m}(\mathrm{C}=\mathrm{N}), 1604-1504 \mathrm{~m}\left(\mathrm{C}=\mathrm{C}_{\mathrm{Ar}}\right), 1283 \mathrm{~m}(\mathrm{C}-\mathrm{O})$. Poly3 IR spectrum $(\mathrm{KBr}) v\left(\mathrm{~cm}^{-1}\right)$ : $3224 \mathrm{~m}(\mathrm{~N}-\mathrm{H}), 1722 \mathrm{~m}$ $(\delta \mathrm{C}=\mathrm{O}$ ester $), 1658 \mathrm{~m}(\mathrm{C}=\mathrm{N}), 1602-1512 \mathrm{~m}\left(\mathrm{C}=\mathrm{C}_{\mathrm{Ar}}\right)$, $1274 \mathrm{~m}(\mathrm{C}-\mathrm{O})$. FTIR spectra of PHZP $(\mathrm{KBr}) v\left(\mathrm{~cm}^{-1}\right)$ : $1743 \mathrm{~m}(\delta \mathrm{C}=\mathrm{O}$ ester $), 1666 \mathrm{~m}(\mathrm{C}=\mathrm{N}), 1604-1503 \mathrm{~m}$ $\left(\mathrm{C}=\mathrm{C}_{\mathrm{Ar}}\right), 1265 \mathrm{~m}(\mathrm{C}-\mathrm{O})$. FTIR spectra of PHAO (Kbr) $v\left(\mathrm{~cm}^{-1}\right): 3438 \mathrm{~m}(\mathrm{~N}-\mathrm{H}), 1768 \mathrm{~m}(\delta \mathrm{C}=\mathrm{O}$ ester $), 1666$ $\mathrm{m}(\mathrm{C}=\mathrm{N}), 1600-1510 \mathrm{~m}\left(\mathrm{C}=\mathrm{C}_{\mathrm{Ar}}\right), 1278 \mathrm{~m}(\mathrm{C}-\mathrm{O})$. FTIR spectra of PHZO $(\mathrm{KBr}) v\left(\mathrm{~cm}^{-1}\right): 1749 \mathrm{~m}(\delta \mathrm{C}=\mathrm{O}$ ester $)$, $1652 \mathrm{~m}(\mathrm{C}=\mathrm{N}), 1604-1510 \mathrm{~m}\left(\mathrm{C}=\mathrm{C}_{\mathrm{Ar}}\right), 1282 \mathrm{~m}(\mathrm{C}-\mathrm{O})$ (Fig. 1).
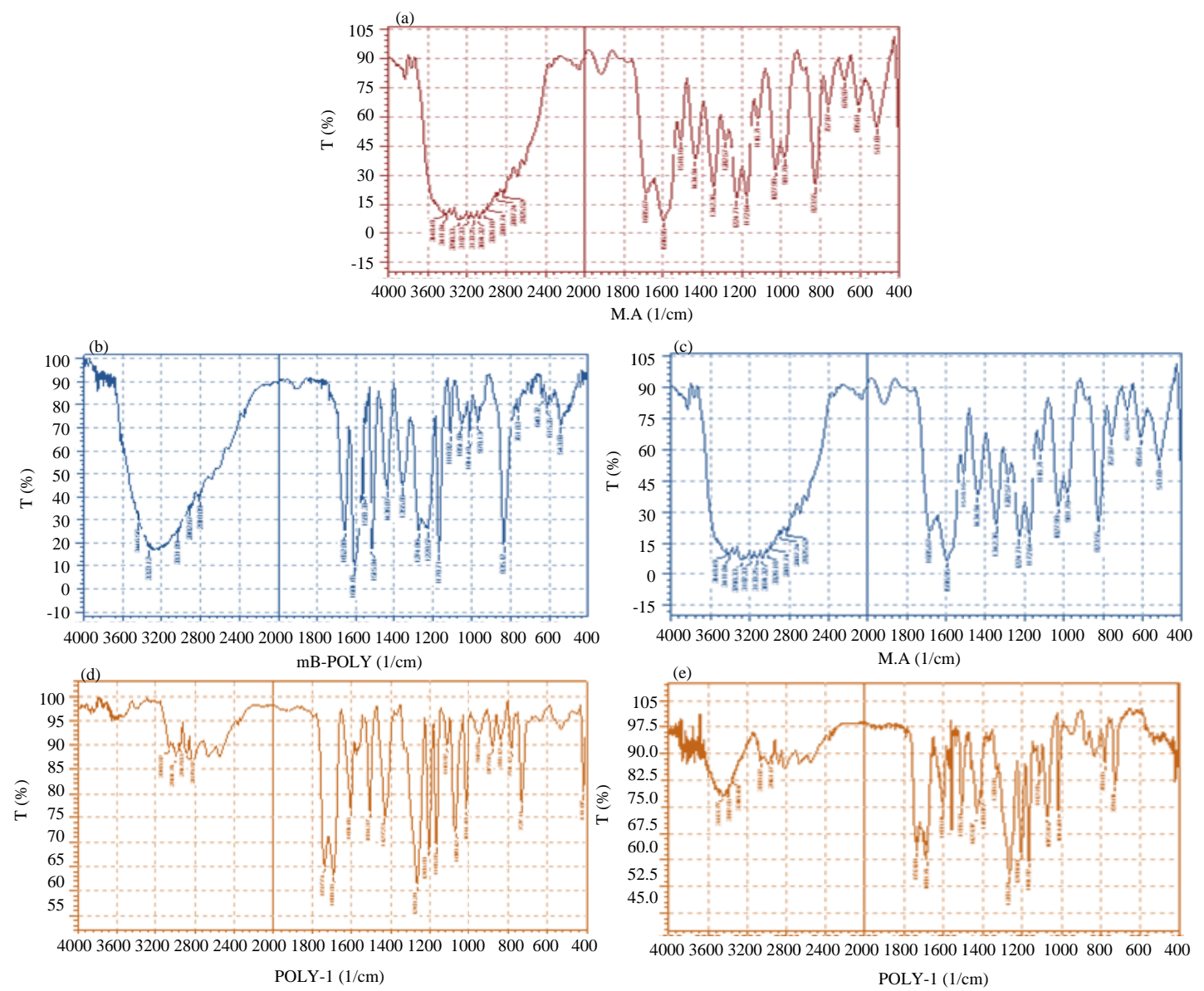

Fig. 1: Continue 

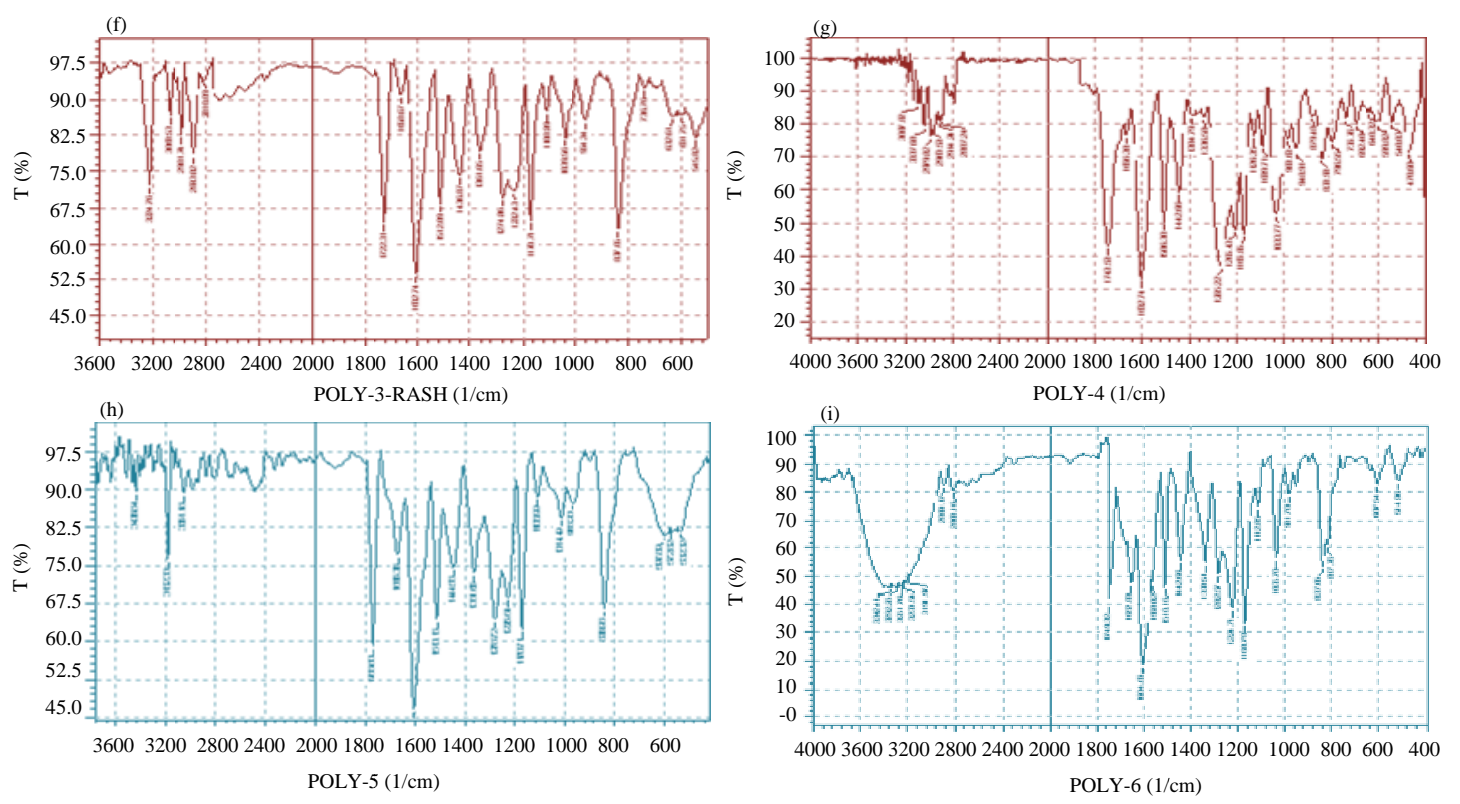

Fig. 1(a-i): FTIR spectrum for copolyesters illustrates the XRD patterns of all copolyester. The diffraction pattern of PHAT and PHZT shows three characteristic peaks at $2=17.4^{\circ}, 26.8^{\circ}$ and $29.3^{\circ}$, indicating a high degree of crystallinity, PHAP, PHZP, PHAO and PHZO shows a very weak reflection at $2=21^{\circ}$. This feature may be attributed to the formation of strong hydrogen bonds between the oxygen or nitrogen for heterocyclic and the bulky aromatic

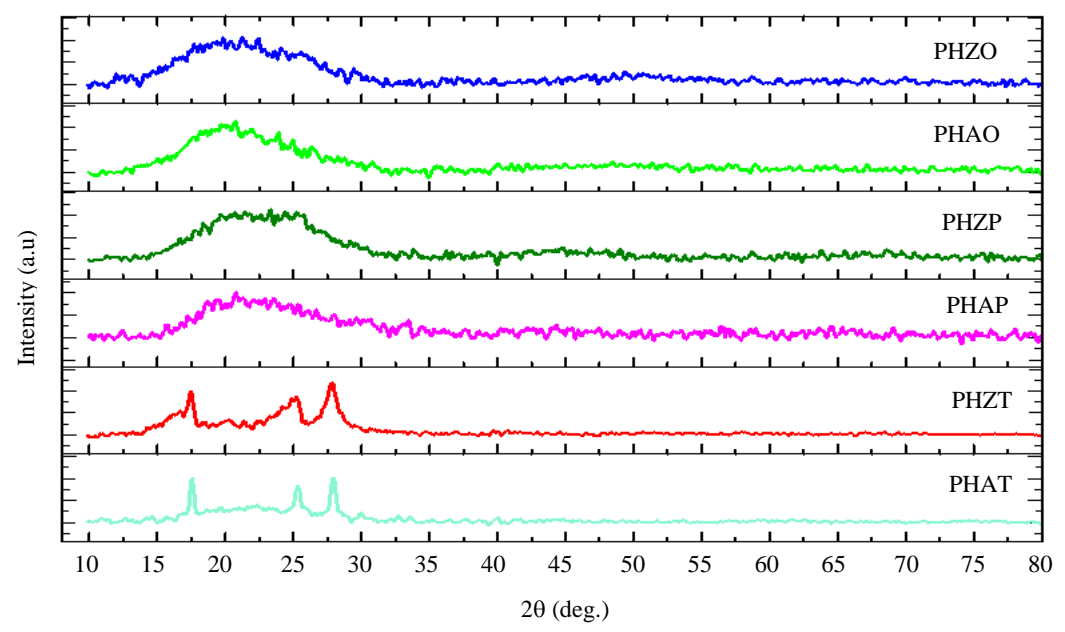

Fig. 2: XRD patterns of copolyesterdgd

\section{X-Ray Diffraction (XRD) analysis}

Thermogravimetric analysis: Thermal properties of the prepared copolyesters were evaluated with Thermo Gravimetric Analysis (TGA) in N2 atmosphere, TGA curves are shown for the PHAH, PHZH and PHAO to indicated four steps of weight loss (Fig. 2).

Primary step beginning at of $272.4-303.7^{\circ} \mathrm{C}$ which is attributed to the removal all of the O2-containing functional groups. The second stage at around $303-450^{\circ} \mathrm{C}$ which happens enough to the removal of most of the oxygen-containing functional groups through the chemical reduction process.

The next stages (3th at about $500^{\circ} \mathrm{C}$ and 4 th at about $600^{\circ} \mathrm{C}$ ) indicate the polymer chain break which can start to the production of gases 29 and the and the glass transition temperature (Tg) at $303 \mathrm{VC}$ of PHAH, 321.3 of PHZH and 321.9 VC of PHAP did determine by Differential Scanning Calorimetry (DSC), so, the polymers showed fairly good thermal stability. 


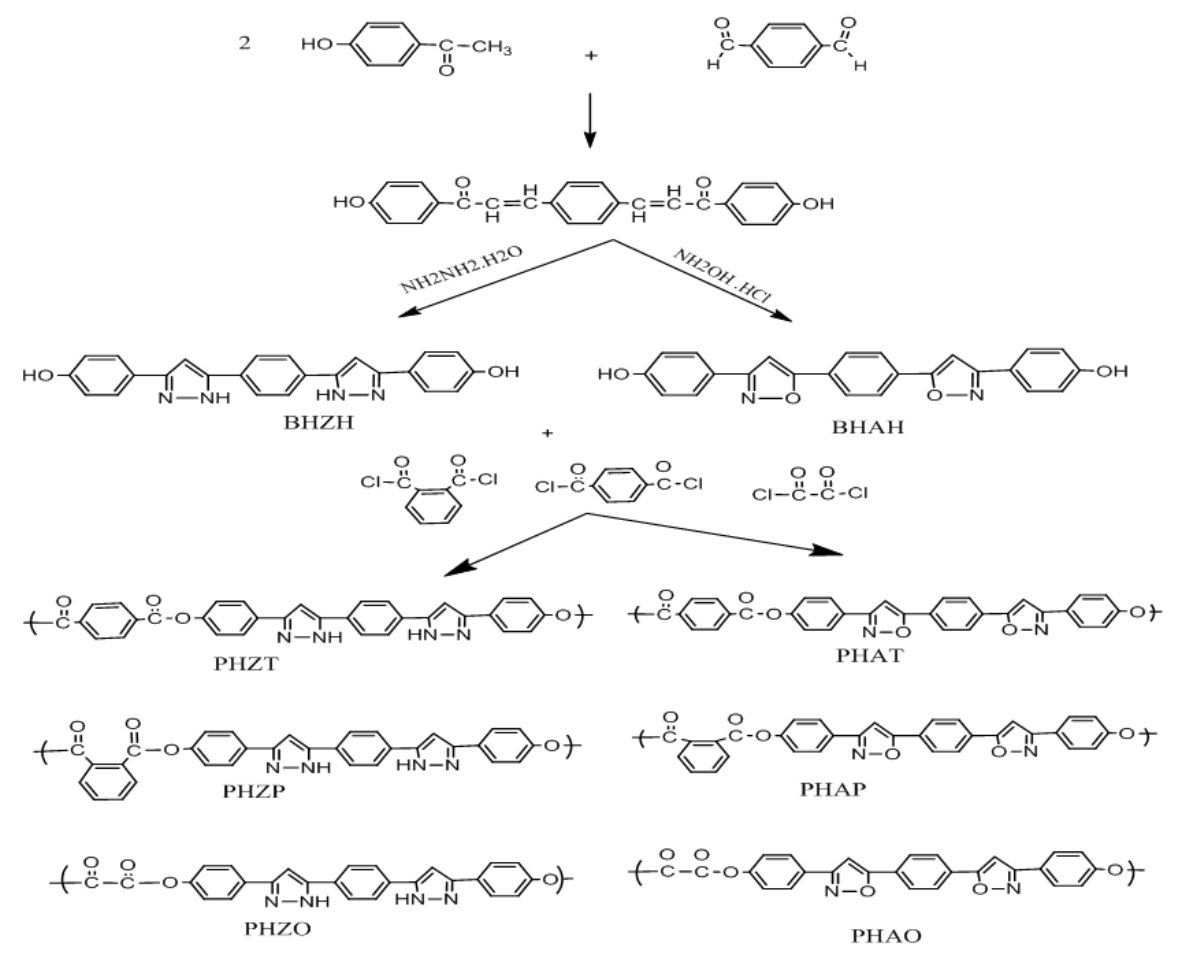

Fig. 3: Measurement of electrical conductivity of the prepared copolyesters at room temperature was carried out using LCR electronic test technique to measure the Inductance (L), Capacitance (C) and Resistance (R) of frequency range $50 \mathrm{~Hz}-1 \mathrm{MHz}$

\section{RESULTS AND DISCUSSION}

Figure 3 shows the chemical structures of the prepared polymers. It is clearly noticed that the chemical structures of the investigated polymers are very important in affecting the measured conductivity. It is also shown that the nature of the chain containing the pyrazolineand dihydroisoxazole is important of the polymers for improving their molecular organization in thin films. The samples with a thickness about 0.2 and $1 \mathrm{~cm}$ diameter were prepared for this study as shown in Table 1.

From the electrical conductivity measured, it may be observed that all the samples are semiconducting in nature and the data showed an enhancing in conductivity via. polyester $(\sigma \sim 10-11 \mathrm{ohm}-1 \mathrm{~cm})$ (Amborski, 1962; Shahab et al., 2009) or poly azomethine ( $\sigma \sim 1.0069 * 10-9$ ohm-1.cm ${ }^{-1}$ ) (Khattab and Al-Chalabi, 2013) by many order of magnitude. In our opinion, this phenomenon may be explained by two manners: firstly: the ester group with unshared pair of electrons can lead to a molecular association with the pyrazoline or dihydroisoxazoleheterocyclic among the chain, this will enhance the movement of charge carriers through the polymer chain then increasing conductivity ( $\mathrm{Su}$ and Kuramoto, 2000).
Table 1: Gives the real, imaginary-permittivity ( $\varepsilon^{\prime}$ and $\left.\varepsilon^{\prime \prime}\right)$ and electrical conductivity of the prepared pure copolymers

\begin{tabular}{llll}
\hline Polymer & $\sigma / \Omega-1 . \mathrm{cm}-1$ & $\varepsilon^{\prime \prime}$ & $\varepsilon^{\prime}$ \\
\hline I & $3.25575 \mathrm{E}-09$ & 1.171595207 & 10.1533513 \\
II & $1.14353 \mathrm{E}-07$ & 41.15058817 & 28.93852895 \\
III & $2.75405 \mathrm{E}-08$ & 9.910581429 & 28.47786394 \\
VI & $1.94048 \mathrm{E}-08$ & 6.982913869 & 21.3675455 \\
V & $2.31687 \mathrm{E}-09$ & 0.833737286 & 7.373638328 \\
VII & $2.71275 \mathrm{E}-08$ & 9.761969897 & 11.75447013 \\
\hline
\end{tabular}

Second: the flexibility can be improved by coupling the pyrazoline or dihydroisoxazoleheterocyclic with an ester group enhancing the conductivity leading to an increase the flexibility of the polymer chain but there should be significant coupling to the electronic degrees of freedom.

It is clear that these results completely exhibited that inserting metal nanoparticles for conduction polymers will increase the electrical conductivity, so when copolyester was mixed with $\mathrm{TiO}_{2}$ nanoparticle, the electrical conductivity was increased because these materials have the advantage of excellent electrical conductivity. These advances could lead to commercial applications in the near future (Dubey and Leclerc, 2011). In addition the ratio of electrical conductivity enhances with increased weight ratio of $\mathrm{TiO}_{2}$ fillers nanosized which revealed the trade-off relationship between the electrical conductivity (Chen et al., 2019) (Table 2). 
The conduction mechanism in our investigated nanocomposites results from the hopping process of charge carriers as a charge transport passes into the polymer in conducting polymer systems, a mechanism of transport is also similar to this in amorphous semiconductors (hopping carrier) (Caseri, 2000; Shumaila et al., 2013). The agent defining the conductivity is the transport movement, along with the carrier concentration. The doping method produces a generous supply of possible carriers but to contribute to conductivity they must be mobile. There are at least three factors contributing to the carrier mobility: single chain or intramolecular transport, interchain transport and interparticle contact (Imam, 2013). These three factors comprise a complicated resistive network which determines the effective mobility of the transmitters. So, the flux and since, the conductivity is prepared on both a microscopic (intro and interchain) and a macroscopic

Table 2: Gives of the real, imaginary-permittivity ( $\varepsilon^{\prime}$ and $\left.\varepsilon^{\prime \prime}\right)$ and electrical conductivity of the prepared copolymers both in the pure state and doped with different concentrations of nanosized $\mathrm{TiO}_{2}$

Polymer/Polymer:

\begin{tabular}{llll}
\hline $\mathrm{TiO}_{2}$ nanoparticles & $\sigma / \Omega-1 . \mathrm{cm}-1$ & $\mathcal{E}^{\prime}$ & $\mathcal{E}^{\prime}$ \\
\hline $\mathbf{I}$ & & & \\
$1: 0.0$ & $3.25575 \mathrm{E}-09$ & 1.171595207 & 10.1533513 \\
$1: 0.1$ & $1.7330 \mathrm{E}-06$ & 0.031288683 & 2.238103238 \\
$1: 0.2$ & $1.00294 \mathrm{E}-06$ & 0.023167975 & 1.83872815 \\
$\mathbf{I I}$ & & & \\
$1: 0.0$ & $1.14353 \mathrm{E}-07$ & 41.15058817 & 28.93852895 \\
$1: 0.1$ & $1.0372 \mathrm{E}-06$ & 0.029948574 & 2.495714515 \\
$1: 0.2$ & $2.41322 \mathrm{E}-06$ & 0.09494689 & 1.680475928 \\
$\mathbf{I I I}$ & & & \\
$1: 0.0$ & $1.40176 \mathrm{E}-06$ & 0.053965383 & 1.690115347 \\
$1: 0.1$ & $1.38363 \mathrm{E}-06$ & 0.042718215 & 3.583742833 \\
$1: 0.2$ & $1.3113 \mathrm{E}-06$ & 0.049946034 & 1.64651479 \\
$\mathbf{V I}$ & & & \\
$1: 0.0$ & $1.94048 \mathrm{E}-08$ & 32.72307089 & 5.074052331 \\
$1: 0.1$ & $1.38145 \mathrm{E}-07$ & 0.012936478 & 3.563767963 \\
$1: 0.2$ & $1.22836 \mathrm{E}-06$ & 0.05566921 & 0.56180452 \\
$\mathbf{V}$ & & & \\
$1: 0.0$ & $2.31687 \mathrm{E}-09$ & 0.833737286 & 7.373638328 \\
$1: 0.1$ & $1.47697 \mathrm{E}-06$ & 0.026574799 & 1.238918383 \\
$1: 0.2$ & $1.0527 \mathrm{E}-06$ & 0.02673162 & 1.684412099 \\
$\mathbf{V I I}$ & & & \\
$1: 0.0$ & $2.71275 \mathrm{E}-08$ & 9.761969897 & 11.75447013 \\
$1: 0.1$ & $1.01102 \mathrm{E}-06$ & 0.019890174 & 1.255692804 \\
$1: 0.2$ & $1.55052 \mathrm{E}-06$ & 0.059692593 & 1.281506943 \\
\hline & & &
\end{tabular}

(interparticle) level, so, the enhanced conductivity observed in samples holding nanosized $\mathrm{TiO}_{2}$ implies either increased charge injection from the electrodes or increased mobility of the injected charge in transit through the sample (Fleming et al., 2005). This behaviour is in an agreement (Al-Maiyaly, 2013; Nesic et al., 1996) as the increasing tendency of conductivity for polyester was also reported by $\mathrm{Xu}$ et al. (2005), Su and Kuramoto (2000). This excitation involves the transfer of electrons from the HOMO to the LUMO of the organic semiconductor for colored compounds which is the case for conjugated polymers (Khattab et al., 2008).

Figure 4 tells the difference of electrical conductivity at room temperature with frequency in the extent of $50 \mathrm{~Hz}^{-1} \mathrm{MHz}$. The data show that the conductivity increases with increasing of frequency and shows a small dip at higher frequencies (Fleming et al., 2005). The same variation was obtained for samples with different $\mathrm{TiO}_{2}$ nanoparticles content $(0.1,0.2)$. The behavior dependent on frequency can be illustrated on the bases of interface charge polarisation (Max-well Wagner-Sillars effect) (Li et al., 2009; Smith, 2009). This phenomenon takes place in heterocyclicssystems like metal-polymer composites owing to the accumulation of charges carriers at the interfaces. Vishnuardhan et al. have reported that the conductivity of pure polypyrrole is $\left(1.26 \times 10^{-4} \mathrm{~s} / \mathrm{cm}\right)$ at 10-5 Hz. Where Fig. 5 showed the electrical conductivity of copolyestersnanocomposite $\left(1.06 \times 10^{-6} \mathrm{~s} / \mathrm{m}\right)$ at the same frequency than pure copolyesters. The improvement of electrical conductivity for nanocomposite comes from the effective dispersion of nanophotoadductin the polypyrrole films which might help the formation of a more efficient network for charge transport in the polypyrrole films, resulting in higher conductivities.

Figure 6 observation tells us that all copolyesters show similar behavior up to $1.13386 \mathrm{E}-06$ at the frequency of $1809.5 \mathrm{~Hz}$ and after that the conductivity increases significantly. With the increase in $\mathrm{TiO}_{2}$ nanoparticles content in copolyesters and increased at higher frequencies. The increase in conductivity is mainly due to an extended chain length of copolyester which helps in a polarisation of charge carriers between localized sites and offers a lot of conductive path.

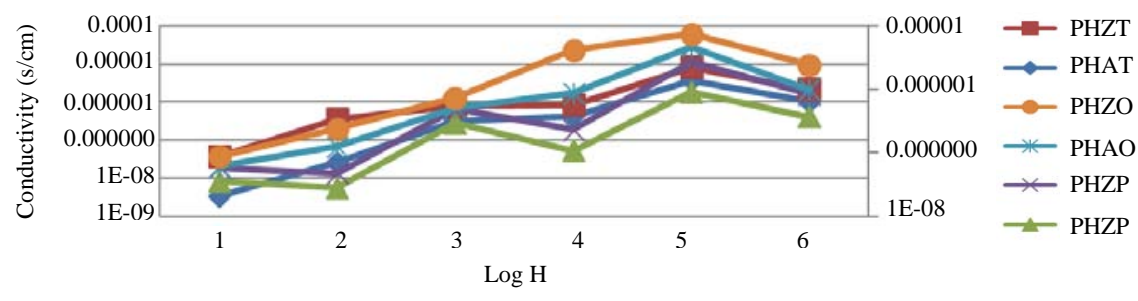

Fig. 4: Electrical conductivity of pure copolyesters with different frequencies 
J. Eng. Applied Sci., 14 (Special Issue 7): 10043-10051, 2019

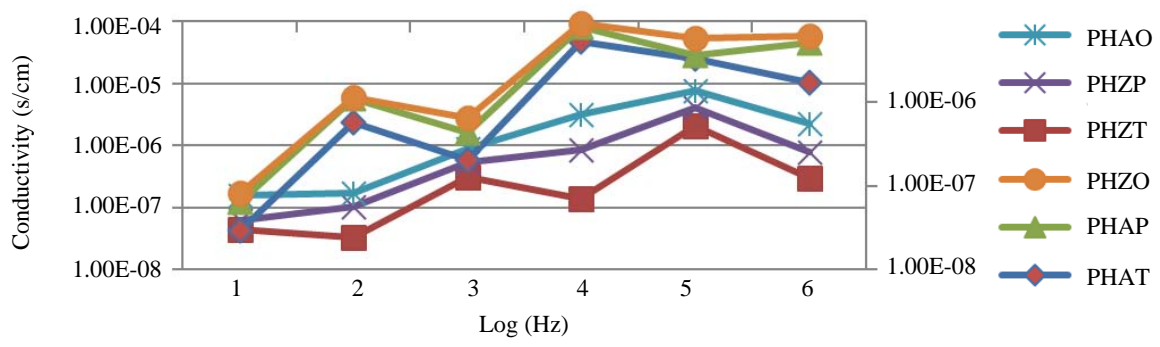

Fig. 5: Electrical conductivity of doped copolyesters by $0.1 \%$ wt. concentration of $\mathrm{TiO}_{2}$ nanoparticles and different frequencies

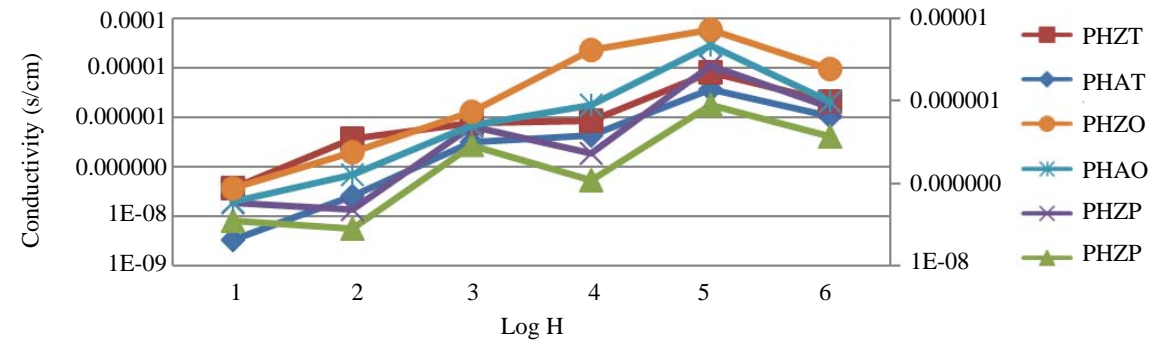

Fig. 6: Electrical conductivity of doped copolyesters by $0.2 \%$ wt. concentration of $\mathrm{TiO}_{2}$ nanoparticles and different frequencies

\section{CONCLUSION}

New monomers containing bispyrazole and bishydroisoxazoleheterocyclics were synthesized and characterized. The structures of the synthesized polymers were confirmed by means of FTIR and NMR spectroscopy. By polycondensation of each monomer with terephthaloylchloride, phthaloyl chloride, oxalyl chloride, six conjugated polyesters have been obtained. TGA showed that the temperatures of maximum weight-loss rate are above $550^{\circ} \mathrm{C}$ and the DSC measurements revealed the existence of glass transition and melting temperatures. Our results indicate that the electrical conductivity of pure and doped polymers by different $\mathrm{TiO}_{2}$ nanoparticle ratios $(0.1,0.2 \%)$ lies in the semiconductors region and in addition, the electrical conductivity increased with the increase of the $\mathrm{TiO}_{2}$ nanoparticle concentration and increase frequency. Also the highest electrical conductivity was obtained for the $\mathrm{PHZO} / \mathrm{TiO}_{2}$ nanoparticle ( $0.2 \% \mathrm{wt}$.).

\section{ACKNOWLEDGEMENT}

The researchers would like to acknowledge the College of Applied Sciences at the University of Samarra for supporting this research and thankful to Mr. Baraa M. Ibrahim AL-Hilali for his suggestions.

\section{REFERENCES}

Al-Maiyaly, B.K.H., 2013. Study the effect of thickness on the electrical conductivity and optical co Ibn AL. Haitham J. Pure Appl. Sci., 26: 159-166.

Amborski, L.E., 1962. Structural dependence of the electrical conductivity of polyethylene terephthalate. J. Polym. Sci., 62: 331-346.

Arango, A.C., S.A. Carter and P.J. Brock, 1999. Charge transfer in photovoltaics consisting of interpenetrating networks of conjugated polymer and TiO2 nanoparticles. Appl. Phys. Lett., 74: $1698-1700$.

Balazs, A.C., T. Emrick and T.P. Russell, 2006. Nanoparticle polymer composites: Where two small worlds meet. Sci., 314: 1107-1110.

Bora, C., P. Bharali, S. Baglari, S.K. Dolui and B.K. Konwar, 2013. Strong and conductive reduced graphene oxide/polyester resin composite films with improved mechanical strength, thermal stability and its antibacterial activity. Compos. Sci. Technol., 87: $1-7$.

Bryan, A.M., L.M. Santino, Y. Lu, S. Acharya and J.M. D’Arcy, 2016. Conducting polymers for pseudocapacitive energy storage. Chem. Mater., 28: 5989-5998.

Caseri, W., 2000. Nanocomposites of polymers and metals or semiconductors: Historical background and optical properties. Macromol. Rapid Commun., 21: 705-722. 
Chandrasekhar, P. and K. Naishadham, 1999. Broadband microwave absorption and shielding properties of a poly (aniline). Synth. Met., 105: 115-120.

Chen, N., C. Lu, Y. Li, C. Long and H. Zhu, 2019. Robust poly (aryl piperidinium)/N-spirocyclic poly (2,6-dimethyl-1, 4-phenyl) for hydroxide-exchange membranes. J. Membr. Sci., 572: 246-254.

Davidenko, N.A. and V.N. Kokozay, 2017. Photophysical properties of film composites of organic polymers with heterometallic complexes of transition metals: A review. Theor. Exp. Chem., 53: 69-92.

Dodabalapur, A., 2006. Organic and polymer transistors for electronics. Mater. Today, 9: 24-30.

Dubey, N. and M. Leclerc, 2011. Conducting polymers: Efficient thermoelectric materials. J. Polym. Sci. Part B. Polym. Phys., 49: 467-475.

Fleming, R.J., T. Pawlowski, A. Ammala, P.S. Casey and K.A. Lawrence, 2005. Electrical conductivity and space charge in LDPE containing $\mathrm{TiO} 2$ nanoparticles. IEEE. Trans. Dielectr. Electr. Insul., 12: 745-753.

Hackett, A.J., J. Malmstrom and J. Travas-Sejdic, 2017. Functionalization of conducting polymers for biointerface applications. Prog. Polym. Sci., 70: 18-33.

Hamming, L.M., R. Qiao, P.B. Messersmith and L.C. Brinson, 2009. Effects of dispersion and interfacial modification on the macroscale properties of $\mathrm{TiO}_{2}$ polymer-matrix nanocomposites. Compos. Sci. Technol., 69: 1880-1886.

Imam, N.G.G., 2013. Structural, magnetic and transport properties of polymer-nanoferrite composites. Ph.D Thesis, Ain Shams University, Cairo, Egypt.

Khattab, A.F. and R.M. AL-Chalabi, 2013. Synthesis and studying the electrical conductivity and optical storage properties of some azo polymers. Tikrit J. Pure Sci., 18: 63-69.

Khattab, A.F., 2007. Effect of polymeric chain flexibility on electrical conductivity of aromatic polyesters. Rafidain J. Sci., 18: 20-27.

Khattab, A.F., 2008. Effect of aromatic ester groups on electrical conductivity of polyazomethine. Rafidain J. Sci., 19: 8-15.

Khattab, A.F., S.F. Mahmood and Y.A. Shahab, 2008. The temperature dependence of the electrical conductivity of some unsaturated copoly (ester-amine) polymers. J. Optoelectron. Adv. Mater., 10: 1463-1467.

Konagaya, S. and M. Tokai, 2000. Synthesis of ternary copolyamides from aromatic diamine (m-Phenylenediamine, diaminodiphenylsulfone), aromatic diamine with Carboxyl or Sulfonic group (3, 5-diaminobenzoic acid, 2, 4-diaminobenzenesulfonic acid) and iso-or Terephthaloyl chloride. J. Appl. Polym. Sci., 76: 913-920.
Konin, M., V. Reddy and A. Bidve, 2018. A study on synthesis, characterization and dielectric properties of PANI-NiO composites. Intl. J. Eng. Dev. Res., 6: 27-31.

Kose, T.D. and S.P. Ramteke, 2012. Studies on synthesis and electrical properties of CdS-polyaniline nanocomposite via oxidation polymerization. Intl. J. Compos. Mater., 2: 44-47.

Kumar, R., S. Singh and B.C. Yadav, 2015. Conducting polymers: Synthesis, properties and applications. Intl. Adv. Res. J. Sci. Eng. Technol., 2: 110-124.

Levitsky, I.A., W.B. Euler, N.A. Tokranova, B. Xu and J. Castracane, 2009. Hybrid solar cells based on nanostructured semiconductors and organic materials. US Patent No. 7,618,838, Patent and Trademark Office, Washington, DC., USA. https://patents.google.com/patent/US7618838B2/en

Li, J., S.I. Seok, B. Chu, F. Dogan, Q. Zhang and Q. Wang, 2009. Nanocomposites of ferroelectric polymers with $\mathrm{TiO} 2$ nanoparticles exhibiting significantly enhanced electrical energy density. Adv. Mater., 21: 217-221.

Lu, X., W. Zhang, C. Wang, T.C. Wen and Y. Wei, 2011. One-dimensional conducting polymer nanocomposites: Synthesis, properties and applications. Prog. Polym. Sci., 36: 671-712.

Mahmood, H.S., 2017. Effect of gamma irradiation and ZnOnano particles on the A.C electrical conductivity of polyaniline. Iraqi J. Phys., 15: 130-135.

Majeed, N.S., 2013. Preparation and identification of some new compounds chalcone and new derivatives of 1, 3-oxazpine. J. Al. Qadisiyah Pure sci., 18: $181-195$.

Nesic, S., J. Postlethwaite and S. Olsen, 1996. An electrochemical model for prediction of corrosion of mild steel in aqueous Carbon dioxide solutions. Corros., 52: 280-294.

Okada, M., M. Tazawa, P. Jin, Y. Yamada and K. Yoshimura, 2006. Fabrication of photocatalytic heat-mirror with $\mathrm{TiO} 2 / \mathrm{TiN} / \mathrm{TiO} 2$ stacked layers. Vac., 80: 732-735.

Phang, S.W., M. Tadokoro, J. Watanabe and N. Kuramoto, 2008. Microwave absorption behaviors of polyaniline nanocomposites containing $\mathrm{TiO} 2$ nanoparticles. Curr. Appl. Phys., 8: 391-394.

Pietrangelo, A., B.C. Sih, B.N. Boden, Z. Wang and Q. Li et al., 2008. Nonlinear optical properties of schiff-base-containing conductive polymer films electro-deposited in microgravity. Adv. Mater., 20: 2280-2284.

Podkoscielny, W. and A. Kultys, 1976. Linear polythioesters I products of interfacial $\mathrm{p}$ o l y c o n d e $\mathrm{n}$ s a $\mathrm{t}$ i o $\mathrm{n}$ o f 4,4'-di(mercaptomethyl)benzophenone with Terephthaloyl, isophthaloyl and Phthaloyl chlorides. J. Polym. Sci. Polym. Chem. Ed., 14: 655-662. 
Potts, J.R., D.R. Dreyer, C.W. Bielawski and R.S. Ruoff, 2011. Graphene-based polymer nanocomposites. Polym., 52: 5-25.

Shahab, Y.A., F.M. Sa'ad and A.F. Khattab, 2009. The effect of the chain sequence distribution, nature of monomers and temperature on the electrical conductivity of some unsaturated amide-ester copolymers. Rafidain J. Sci., 20: 38-51.

Shumaila, M. Alam, A.M. Siddiqui and M. Husain, 2013. Synthesis, characterization and properties of Se nanowires intercalated polyaniline/Se nanocomposites. Express Polym. Lett., 7: 723-732.

Smith, R.C., 2009. Mechanistic electrical behavior of crosslinked polyethylene/silica nanocomposites. Ph.D Thesis, Rensselaer Polytechnic Institute, Troy, New York, USA.

Su, S.J. and N. Kuramoto, 2000. Processable polyaniline-titanium dioxide nanocomposites: Effect of Titanium dioxide on the conductivity. Synth. Met., 114: $147-153$.
Sudirman, M. Anggaravidya, E. Budianto and I. Gunawan, 2012. Synthesis and characterization of polyester-based nanocomposite. Procedia Chem., 4: 107-113.

Vilcakova, J., P. Saha and O. Quadrat, 2002. Electrical conductivity of Carbon fibres/polyester resin composites in the percolation threshold region. Eur. Polym. J., 38: 2343-2347.

Wang, J.H.H., 2015. Conductivity, morphology and dynamics of single-ion conducting random and block copolymers. Ph.D Thesis, Pennsylvania State University, Pennsylvania, USA.

Xu, J.C., W.M. Liu and H.L. Li, 2005. Titanium dioxide doped polyaniline. Mater. Sci. Eng. C., 25: 444-447.

Yavuz, A.G. and A. Gok, 2007. Preparation of TiO2/PANI composites in the presence of surfactants and investigation of electrical properties. Synth. Met., 157: 235-242. 